\title{
Thirst perception and arginine vasopressin production in a kindred with an activating mutation of the type 2 vasopressin receptor: the pathophysiology of nephrogenic syndrome of inappropriate antidiuresis
}

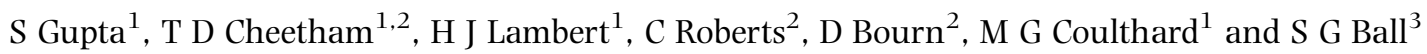 \\ ${ }^{1}$ Department of Paediatrics, Royal Victoria Infirmary, Newcastle upon Tyne Hospitals NHS Trust, Newcastle upon Tyne, NE1 4LP, UK, ${ }^{2}$ The Institute \\ of Human Genetics, International Centre for Life, Newcastle University, Central Parkway, Newcastle upon Tyne, NE1 3BZ, UK and ${ }^{3}$ Department of \\ Endocrinology and Royal Victoria Infirmary, Newcastle upon Tyne Hospitals NHS Trust, Newcastle University, Newcastle upon Tyne, NE1 4LP, UK \\ (Correspondence should be addressed to T D Cheetham at Department of Paediatrics, Institute of Human Genetics, International Centre for Life, \\ Royal Victoria Infirmary, Newcastle upon Tyne Hospitals NHS Trust, Newcastle University; Email: tim.cheetham@nuth.nhs.uk)
}

\begin{abstract}
Background: Activating mutations of the vasopressin receptor gene on the $\mathrm{X}$ chromosome cause the nephrogenic syndrome of inappropriate antidiuresis (NSIAD). We describe a male child who presented with persistent hyponatraemia and whose mother was also found to be hyponatraemic. She had learnt to avoid excess fluid consumption because of associated malaise. Both individuals had a subnormal ability to excrete a water load with mother also demonstrating a heightened sense of thirst at low serum osmolalities.

Results: Mother and child were found to have the previously characterised activating mutation (p.Arg137Cys) of the arginine vasopressin receptor type 2 gene (AVPR2), but had measurable levels of AVP when hyponatraemic.

Conclusions: We conclude that female carriers of activating mutations of the vasopressin receptor are susceptible to hyponatraemia and therefore need to be provided with advice regarding fluid intake. An altered thirst perception may increase susceptibility to hyponatraemia. We confirm that the presence of measurable amounts of AVP in patients with hyponatraemia does not exclude the diagnosis of NSIAD.
\end{abstract}

European Journal of Endocrinology 161 503-508

\section{Introduction}

The arginine vasopressin (AVP) type 2 receptor (V2R) is a $\mathrm{G}$ protein-coupled receptor expressed in the collecting ducts of the renal tubule. AVP binds to the V2R and stimulates water reabsorption by the activation of intracellular cyclic AMP. Inactivating mutations of the V2R gene (AVPR2) on the X-chromosome result in congenital nephrogenic diabetes insipidus in males (1). Patients with nephrogenic diabetes insipidus cannot generate appropriately concentrated urine and are susceptible to hypernatraemic dehydration if denied free access to hypotonic fluid. To date, more than 180 inactivating mutations of $A V P 2 R$ have been described. Although female carriers of $A V P 2 R$ mutations were originally thought to be asymptomatic, it is clear that their ability to concentrate urine is compromised.

Feldman et al. (2) have recently reported hemizygous gain of function point mutations (p.Arg137Cys and p.Arg137Leu) in AVPR2 in two male infants who presented with a picture suggestive of the syndrome of inappropriate antidiuretic hormone production (SIADH), but in the presence of undetectable AVP levels. They called this condition the "nephrogenic syndrome of inappropriate antidiuresis' (NSIAD). The mother of one of the boys was heterozygous for the p.Arg137Cys mutation but had normal plasma sodium and plasma and urine osmolalities, suggesting rescue of the phenotype through co-expression of the normal allele, thereby indicating a gene dosage effect. More recently, Decaux et al. (3) have described the mutation p.Arg137Cys in three hemizygous adult males and four heterozygous adult females in a large five generation family identified during the phase III clinical trials of oral inhibitors of V2R. They identified high phenotypic variability in adult males and females in the presence of this mutation.

Here we describe a male infant with hyponatraemia in early infancy who was found to have NSIAD. The subsequent studies conducted in mother and child 
provide insight into pathophysiology of NSIAD including the significance of an activating mutation of AVPR2 in female heterozygotes.

\section{Case histories}

A male infant presented at 7 months of age with a generalised tonic clonic seizure. He had been exclusively breastfed until 6 months of age before being changed to bottle feeds. Initial investigations revealed hyponatraemia with a plasma sodium of $120 \mathrm{mmol} / \mathrm{l}$. The fractional excretion of sodium (FeNa) was $4.2 \%$ and his plasma osmolality was $250 \mathrm{mOsm} / \mathrm{l}$. Plasma potassium, renal function, blood pressure and 17-OH progesterone were all normal. Atrial natriuretic peptide (ANP) was $16 \mathrm{pmol} / \mathrm{l}$ (reference range $<11 \mathrm{pmol} / \mathrm{l}$ ). Renal ultrasound scan and micturating cystourethrogram did not reveal any pathology. In view of the high FeNa and ANP level, he was initially thought to have a salt-losing nephropathy. Plasma sodium stabilised between 134 and $141 \mathrm{mmol} / \mathrm{l}$ on treatment with oral sodium supplementation in the range of $18-22 \mathrm{mmol} / \mathrm{kg}$ per day, although FeNa remained high with measurements between 1.0 and $9.1 \%$.

Shortly afterwards, the child's 33-year-old mother was noted to have persistent hyponatraemia $(128 \mathrm{mmol} / \mathrm{l})$ on routine medical review. She did not have any significant past medical history and she was not on any regular medication. Clinical examination was normal. Routine investigations, including thyroid function, were normal and she demonstrated a normal cortisol response to $250 \mu \mathrm{g}$ synacthen. Urinary sodium was $143 \mathrm{mmol} / \mathrm{l}$ at the time of corresponding plasma sodium of $130 \mathrm{mmol} / \mathrm{l}$ with a FeNa of $0.76 \%$. Further systematic enquiry revealed that large fluid intakes had made her feel unwell, and she had learnt to avoid excess fluid intake. Furthermore, she had become markedly oedematous during pregnancy.

\section{Methods}

\section{Assessment of free water excretion: water load test}

Free water excretion was assessed by water load test according to a standard protocol (4). In brief, an oral water load $(20 \mathrm{ml} / \mathrm{kg})$ was administered over 15 minutes. Urine output, urine osmolality, plasma osmolality and plasma AVP were measured at baseline and then hourly for $4 \mathrm{~h}$. Normal subjects excrete $70-92 \%$ of ingested water load in the $4-h$ period. In the case of the child, a nasogastric (NG) tube was inserted to facilitate administration of the water load, and the test commenced $1 \mathrm{~h}$ after NG tube insertion to avoid data misinterpretation because of nausea-induced non-osmoregulated AVP secretion.

\section{Assessment of osmoregulated thirst and AVP production by graded hyperosmolar stimulation with hypertonic saline}

Thirst and AVP response to graded hypertonic stimulation were assessed in the mother by standard methods (4). In brief, hypertonic $5 \%$ saline $(850 \mathrm{mmol} / \mathrm{l})$ was infused over a period of $2 \mathrm{~h}$ at a rate of $0.06 \mathrm{ml} / \mathrm{kg}$ per min. Plasma osmolality and AVP were assessed at baseline and at $30 \mathrm{~min}$ intervals during the infusion. Thirst was assessed in parallel using a validated visual analogue scale (4). Plasma AVP and thirst were related to standardised normal reference ranges determined in normal volunteers.

Plasma AVP was measured by in-house RIA using a sheep anti-AVP antibody with an inter-assay coefficient of variation of $5-7 \%$. Lower limit of detection of the assay is $0.3 \mathrm{pmol} / \mathrm{l}(4)$.

\section{AVPR2 analysis (accession number NM_000054.2)}

Exon 8 of AVPR2 was amplified from genomic DNA using the forward primer ACT TGT GCC TGG CCG ACC TG and the reverse primer AGC AGG CCC AGC AGT CAG TG. The PCR conditions used were initial denaturation at $95{ }^{\circ} \mathrm{C}$ for $7 \mathrm{~min}$, followed by 30 cycles of $95^{\circ} \mathrm{C}$ for $45 \mathrm{~s}, 62{ }^{\circ} \mathrm{C}$ for $45 \mathrm{~s}$ and $72{ }^{\circ} \mathrm{C}$ for $1 \mathrm{~min}$. PCR products were sequenced using dye terminator cycle sequencing Quick Start kit (Beckman Coulter, Fullerton, CA, USA) and run on the Beckman Coulter CEQ8000 Genetic Analysis System.

\section{Results}

\section{Water load testing}

Baseline biochemistry at presentation is summarised in Table 1.

Free water clearance was reduced in the child with only $19 \%$ of a water load being excreted over a $4-\mathrm{h}$ period following ingestion (normal range 70-92\%). The mother also demonstrated reduced clearance of a water load, excreting only $47 \%$ of the ingested load over the corresponding time period. The relationship between serum osmolality and urine osmolality and the relationship between serum osmolality and AVP production in mother and child are shown in Table 2. Plasma AVP was detectable throughout the water load test in both subjects, with nadir values of 0.7 and $0.4 \mathrm{pmol} / \mathrm{l}$ for the child and mother respectively.

\section{Maternal thirst response to hyperosmolar stimulation}

Maternal plasma vasopressin data showed detectable plasma AVP at values of plasma osmolality below the normal osmolar threshold for AVP release (around 
Table 1 Investigations at presentation.

\begin{tabular}{lcc}
\hline Name of test (units) & $\begin{array}{c}\text { Child } \\
\text { (age } 7 \text { months) }\end{array}$ & $\begin{array}{c}\text { Mother } \\
\text { (age 33 years) }\end{array}$ \\
\hline $\mathrm{Na} \mathrm{(mmol/l)}$ & 120 & 130 \\
$\mathrm{~K}(\mathrm{mmol} / \mathrm{l})$ & 4.9 & 4.5 \\
$\mathrm{U}(\mathrm{mmol} / \mathrm{l})$ & 2.0 & 3.5 \\
$\mathrm{Cr}(\mu \mathrm{mol} / \mathrm{l})$ & 31 & 75 \\
$\mathrm{Ca}(\mathrm{mmol} / \mathrm{l})$ & 2.49 & 2.39 \\
$\mathrm{TSH}(\mathrm{mlU} / \mathrm{l})$ & 0.7 & 0.93 \\
Free thyroxine (pmol/l) & 15 & 16 \\
Plasma osmolality & 247 & 257 \\
$\quad(\mathrm{mOsm} / \mathrm{kg})$ & & \\
17-OHP (nmol/l) & $<5$ & 8.6 \\
Synacthen test & 912 & 985 \\
$\quad(\mathrm{max} \mathrm{cortisol} \mathrm{nmol} / \mathrm{l})$ & & \\
Renin (ng/ml per h) & 0.3 & 245 \\
Aldosterone (pmol/l) & 250 & 143 \\
U Na (mmol/l) & 130 & 87 \\
U K (mmol/l) & 5 & 10.8 \\
U Cr (mmol/l) & 0.8 & 0.76 \\
FeNa (\%) & 4.2 & 639 \\
Urine osmolality (mOsm/l) & 309 & \\
\hline
\end{tabular}

$284 \mathrm{mOsm} / \mathrm{kg}$; Fig. 1A). These data are consistent with persistent low level AVP production that is not suppressible even at low plasma osmolality. No nausea was reported or observed during hypertonic saline infusion, but the mother experienced thirst at a low plasma osmolality indicating an increased thirst component compared with normal. This sensation persisted at the same level as plasma osmolality rose into the reference range (Fig. 1B).

\section{Identification of a p.Arg137Cys mutation associated with hyponatraemia}

DNA from the child and his mother was tested by direct sequencing of AVPR2 from bases c.274 to c.564 (codons 92-188): the portion of AVPR2 shown previously to harbour gain of function mutations. Sequencing in the child confirmed a p.Arg137Cys mutation in AVPR2 (obligate hemizygote). His mother was heterozygote for the same mutation. The other maternal AVPR2 allele was confirmed as wild-type sequence.

Table 2 Results of water loading test.

\begin{tabular}{lll}
\hline & Child & Mother \\
\hline Age (years) & 4 & 34 \\
Weight $(\mathrm{kg})$ & 18 & 67.8 \\
Water intake $(\mathrm{ml})$ & 370 & 1356 \\
Urine volume $(\mathrm{ml} / 4 \mathrm{~h})$ & 70 & 640 \\
Urine volume/water intake $(\%)$ & 19 & 47 \\
Plasma sodium $(\mathrm{mmol} / \mathrm{l})(\mathrm{B} \rightarrow \mathrm{M})$ & $136 \rightarrow 131$ & $134 \rightarrow 130$ \\
Plasma AVP $(\mathrm{pmol} / \mathrm{l})(\mathrm{B} \rightarrow \mathrm{M})$ & $1.0 \rightarrow 0.7$ & $1.5 \rightarrow 0.4$ \\
Plasma osmolality $(\mathrm{mOsm} / \mathrm{kg})(\mathrm{B} \rightarrow \mathrm{M})$ & $285 \rightarrow 274$ & $257 \rightarrow 248$ \\
Urine osmolality $(\mathrm{mOsm} / \mathrm{kg})(\mathrm{B} \rightarrow \mathrm{M})$ & $938 \rightarrow 930$ & $447 \rightarrow 328$
\end{tabular}

$B$, baseline values; $M$, minimal value during test.
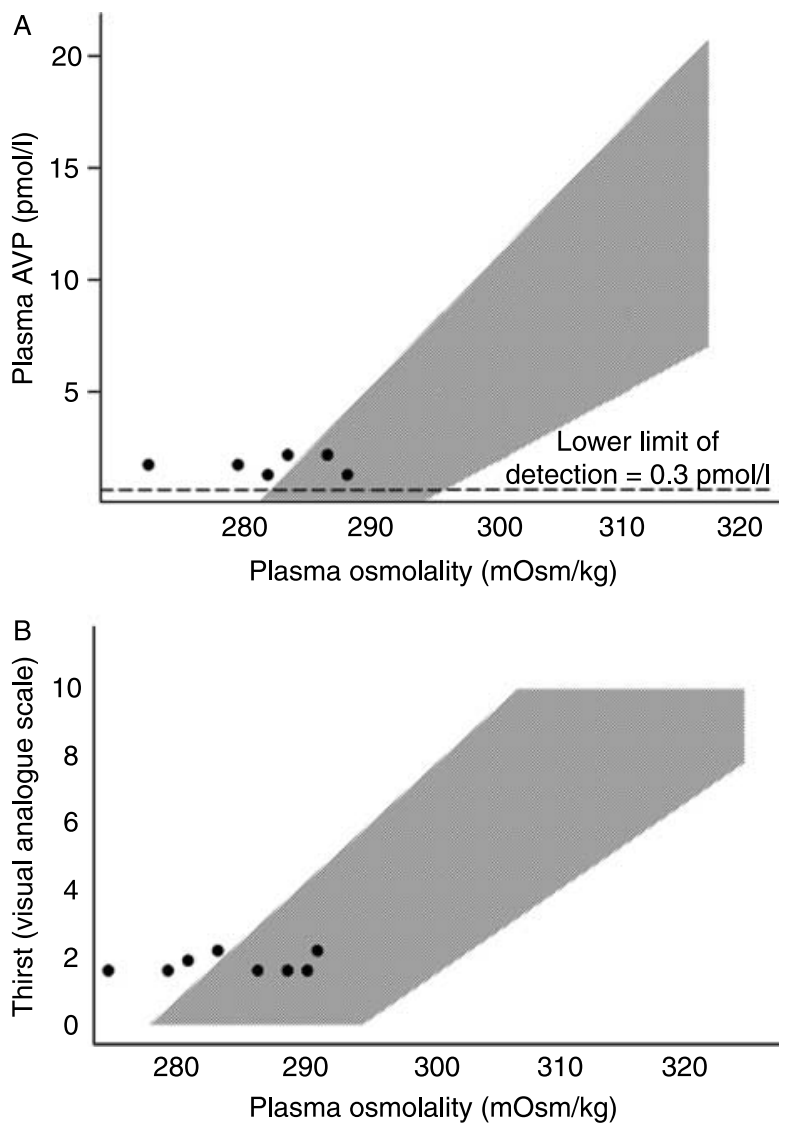

Figure 1 (A) Maternal plasma AVP response plotted against plasma osmolality following graded hyperosmolar stimulation. There is persistent AVP production at a plasma osmolality below the functional osmolar threshold. (B) Maternal thirst response plotted against plasma osmolality during hypertonic saline infusion. The response demonstrates thirst at inappropriately low plasma osmolalities.

\section{Discussion}

Gain of function mutations of a range of G-proteincoupled receptors that induce constitutive receptor activation in the absence of a hormonal stimulus are described. Such mutations can give rise to diseases such as thyrotoxicosis (an abnormal thyroid-stimulating hormone receptor), familial male-limited precocious puberty (an abnormal LH receptor) and hypercalcuric hypocalcaemia (an abnormal Ca sensing receptor) (5, 6). This group of disorders has been expanded further by the description of activating mutations of $\mathrm{V} 2 \mathrm{R}$ leading to NSIAD (2). Details of the 12 patients now reported with NSIAD are summarised in Table 3.

Our case demonstrates that female carriers of such mutations of AVPR2 may develop a clinical and biochemical phenotype with an abnormal response to a water load. This is in contrast to a previous report (2), but in keeping with the findings of Decaux et al. (3) who demonstrated an abnormal water load test or episodes of hyponatraemia in three out of four female heterozygotes 


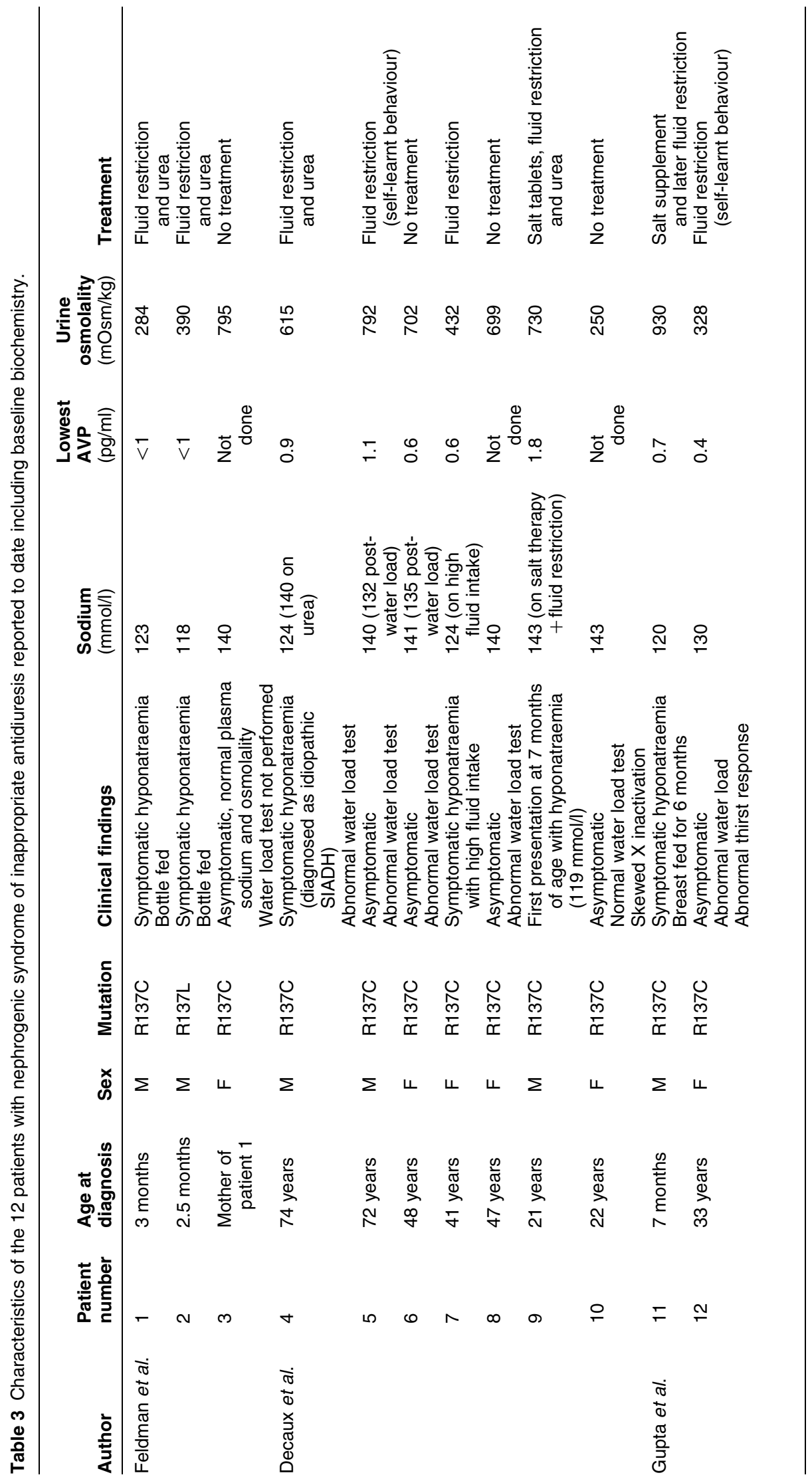


from their kindred. A skewed X inactivation pattern was identified in the fourth, asymptomatic individual. Perhaps of greater interest in our report is the assessment of thirst dynamics and AVP production in response to graded hypertonic stimulation. This has not been assessed by previous investigators, and our studies demonstrate that both AVP and thirst dynamics can be abnormal in patients with activating V2R mutations. We have shown that AVP production can persist despite the low plasma sodium and plasma osmolality associated with V2R activation. This may represent nonosmoregulated AVP production, although the fact that AVP was detectable under most circumstances in the absence of feelings of nausea is still surprising. The osmolality of voided urine will normally reflect AVP production over the preceding hours rather than AVP levels at one particular moment in time, but it is of note that maternal AVP levels were relatively low for a given urine osmolality in keeping with constitutive V2R activation.

The relationship between sodium and vasopressin in the SIADH has been categorised into four main groups (A-D) (4). Type A represents a picture with seemingly random AVP secretion, type $B$ represents a picture where there is a 'reset osmostat', type C indicates AVP secretion that appears to be fixed at inappropriately high levels under hypotonic conditions, but then increases normally when the osmolality exceeds the usual threshold values, and finally type D SIADH represents antidiuresis in the absence of AVP. While it might be assumed that patients with NSIAD will fall into category D, clinicians need to be aware that patients with activating mutations of AVPR 2 could also potentially have been grouped into category $\mathrm{B}$.

The maternal thirst response curve indicated an increased thirst component compared with normal at lower plasma osmolalities. This could help to explain significant fluid ingestion and maintenance of hyponatraemia at low plasma osmolalities, although the history indicated that ingestion of very large fluid volumes still resulted in her feeling unwell. Whether this phenomenon is associated with V2R activation is unclear, although the vasopressin receptors $1 \mathrm{a}$ and $1 \mathrm{~b}$ (V1aR and V1bR) are known to be expressed in the CNS including hypothalalmus (7). The thirst response in normal subjects has been studied in detail, and we can be confident that maternal thirst perception was abnormal (4). We suspect that the suppressed renin activity and measurable aldosterone levels (within our local reference range) seen in the mother reflect an abnormally high total body water content. A similar biochemical picture was described by Feldman et al. (2) in one of their patients (patient 2 in Table 3 ) and by Decaux et al. (3) in a lady who was dieting with an associated high fluid intake prediagnosis (patient 7 in Table 3). Renin levels are not always low at the time of hyponatraemia in NSIAD, which underlines the importance of exercising caution when interpreting the results of a single set of random samples. It would be useful to establish whether sodium concentrations altered in pregnancy, but unfortunately maternal electrolytes were not determined at this time.

It is interesting to note that the index case was asymptomatic during the period of breastfeeding up to 6 months, but presented with hyponatraemic seizures soon after being changed to bottle feeds. This may indicate that infants breastfed 'on demand' can regulate their fluid intake more effectively, in contrast to bottle fed babies who are frequently offered an obligate volume of feed. The relatively low urine osmolality of the very young child may also reduce susceptibility to hyponatraemia, as highlighted by Decaux et al. (3). The serum sodium value increased as the index case matured, presumably also reflecting a relative reduction in fluid intake per square metre with advancing years. Children with NSIAD have been managed successfully with oral urea (8), and although our child's sodium concentrations rose with sodium supplements and the passage of time, oral urea might have been an appropriate therapy had he remained symptomatic. Urea is not licensed for use in the management of hyponatraemia in the UK.

In summary, a clinical picture of hyponatraemia with ongoing AVP release is compatible with an activating mutation in AVPR2. Hyponatraemia may reflect altered thirst as well as altered renal water handling. Although water restriction improves plasma sodium concentrations in such individuals, this could compromise calorie intake in young infants. Finally, female heterozygotes may need to exercise some caution with regard to their fluid intake throughout their lives.

\section{Declaration of interest}

There is no conflict of interest that could be perceived as prejudicing the impartiality of the research reported.

\section{Funding}

This research did not receive any specific grant from any funding agency in the public, commercial or not-for-profit sector.

\section{References}

1 Knoers VAM. Hyperactive vasopressin receptors and disturbed water homeostasis. New England Journal of Medicine 2005352 1847-1850.

2 Feldman BJ, Rosenthal SM, Vargas GA, Fenwick RG, Huang EA, Matsuda-Abedini M, Lustig RH, Mathias RS, Portale AA, Miller WL \& Gilelman SE. Nephrogenic syndrome of inappropriate antidiuresis. New England Journal of Medicine 2005352 1884-1890.

3 Decaux G, Vandergheynst F, Bouko Y, Parma J, Vassart G \& Vilain C. Nephrogenic syndrome of inappropriate antidiuresis in adults: high phenotypic variability in men and women from a large pedigree. Journal of the American Society of Nephrology 200718 606-612.

4 Ball S. Vasopressin and disorders of water balance: the physiology and pathophysiology of vasopressin. Annals of Clinical Biochemistry $2007 \mathbf{4 4} 417-431$. 
5 Kopp P, van Sande J, Parma J, Duprez L, Gerber H, Joss E, Jameson JL, Dumont JE \& Vassart G. Congenital hyperthyroidism caused by a mutation in the thyrotropin-receptor gene. New England Journal of Medicine 1995332 150-154.

6 Kremer H, Martens JWM, van Reen M, Verhoef-Post M, Wit JM, Otten BJ, Drop SLS, Delemarre-van de Waal HA, Pombo-Arias M, De Luca F, Potau N, Buckler JMH, Jansen M, Parks JS, Latif HA, Moll GW, Epping W, Saggese G, Mariman ECM, Themmen APN \& Brunner HG. A limited repertoire of mutations of the luteinizing hormone (LH) receptor gene in familial and sporadic patients with male LH-independent precocious puberty. Journal of Clinical Endocrinology and Metabolism 199984 1136-1140.
7 Serradeil-Le Gal C, Wagnon J, Valette G, Garcia G, Pascal M, Maffrand JP \& Le Fur G. Nonpeptide vasopressin receptor antagonists: development of selective and orally active V1a, V2 and V1b receptor ligands. Progress in Brain Research 2002139 197-210.

8 Huang EA, Feldman BJ, Schwartz ID, Geller DH, Rosenthal SM \& Gitelman SE. Oral urea for the treatment of chronic syndrome of inappropriate antidiuresis in children. Journal of Pediatrics 2006 $148128-131$.

Received 10 June 2009

Accepted 18 June 2009 